УДК $81 ' 373.7,811.111,811.112 .2,811.161 .1$

DOI: $10.17223 / 19986645 / 45 / 10$

\title{
Н.П. Соболева
}

\section{ЛИНГВОКУЛЬТУРОЛОГИЧЕСКИЕ АСПЕКТЫ КОНТЕКСТУАЛЬНОГО ИСПОЛЬЗОВАНИЯ ФРАЗЕОЛОГИЗМОВ В РЕКЛАМНЫХ СЛОГАНАХ}

\begin{abstract}
Статья посвящена сопоставительному анализу аспектов узуального и окказионального функционирования ФЕ в контексте сочиальных и коммерческих слоганов для товаров, услуг и полнометражных кинофильмов на русском, английском и немецком языках с иелью выявления основных тенденций в контекстуальной реализации фразеологизмов с учетом лингвокультурологического подхода. Количественный анализ практического материала, основанный на сопоставлении, осуществляется в вертикальном и горизонтальном срезах.

Ключевые слова: фразеологическая единица, слоган, окказиональное использование, культурно-национальная специифика.
\end{abstract}

\section{1. Введение}

Фразеология представляет собой особую область языкознания, в рамках которой наиболее тесным образом переплетаются язык, культура, история и картина мира того или иного этноса. Фразеологизмы в своей способности отражать действительность характеризуются образно-ситуативной мотивированностью. Иными словами, фразеологические единицы (ФЕ) преломляют фрагменты реальности посредством образного и экспрессивно-оценочного восприятия важных для этноса явлений. Согласно определению В.Н. Телии «<..> средством воплощения культурно-национальной специфики фразеологизмов служит образное основание (в том числе и включающее в себя культурно-маркированные реалии), а способом указания на эту специфику является интерпретация образного основания в знаковом культурно-национальном «пространстве» данного языкового сообщества» [1. С. 215].

Фразеологизмы, являясь своеобразными проводниками в ту или иную культуру, часто фигурируют в языке рекламы, который предполагает узуальное и окказиональное использование ФЕ в качестве вербального средства аттракции реципиентов. Целью настоящего исследования является сопоставительный анализ особенностей узуального и окказионального использования ФЕ в контексте социальных и коммерческих слоганов для товаров, услуг и полнометражных кинофильмов на русском, английском и немецком языках для выявления основных тенденций в контекстуальной реализации фразеологизмов с учетом лингвокультурологического подхода. Сопоставительный характер данной работы, реализованной на материале слоганов на трех языках, а также комплексный подход к анализу практического материала обуславливают актуальность исследования.

В качестве материала было рассмотрено 18 тысяч слоганов на русском, английском и немецком языках. Описание анализируемого материала строит- 
ся в виде таблицы, где по вертикали располагаются контекстуальные конфигурации, а по горизонтали - языки, в рамках которых реализуется анализ (см. табл. 1, 2). Количественный анализ слоганов для коммерческой и социальной разновидностей рекламы, основанный на сопоставлении, осуществляется в вертикальном (см. табл. 1) (все контекстуальные конфигурации рассматриваются в рамках одного языка) и горизонтальном (см. табл. 2) (каждая контекстуальная конфигурация отдельно рассматривается в трех языках) срезах.

\section{2. Контекстуальная реализация ФЕ в рекламных слоганах}

2.1.Прочентное соотношение узуального и окказионального употребления $\Phi E$

Фразеологизмы, используемые в рекламных кампаниях, редко употребляются без семантических или структурно-семантических преобразований, отсюда возникает повышенный интерес ученых к данной проблеме: анализ контекстуального использования ФЕ проводится исследователями в данной области на различном языковом материале. В.Г. Костомаров в рамках очерков о современной русской стилистике в один ряд с другими (художественными, научными и т.д.) ставит язык рекламы, в частности рекламных слоганов. Исследователь отмечает, что, несмотря на различную культурную ценность, слоган, как и любой текст, обладает теми же признаками: связностью, завершенностью, информативностью и пр.. По словам В.Г. Костомарова, «Содержательная целостность и завершенность подобных текстов такова, что иной раз служит их облагораживанию и вхождению в культуру» [2. С. 40].

Важно отметить, что текст рекламы часто сопоставляется с текстом художественных произведений. Последний являет собой богатый материал для лингвистического анализа. Особый интерес представляют статистические данные, отражающие процентное соотношение узуального и окказионального употребления ФЕ в литературных произведениях. А. Начисчионе приводит в качестве примера работы Д. Лоренса и Д. Чосера. Согласно результатам анализа около $30 \%$ фразеологизмов, реализуемых в литературных произведениях именитых писателей, подвергаются стилистическим трансформациям [3. С. 24].

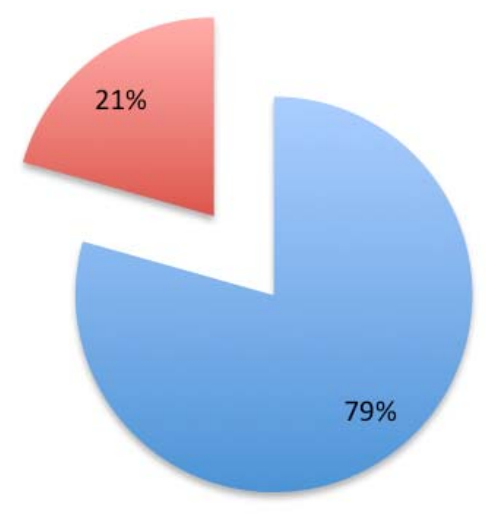

Рис. 1. Соотношение узуальной конфигурации и окказиональной конфигурации первой и второй степени в коммерческой рекламе 
Рис. 2. Соотношение узуальной конфигурации и окказиональной конфигурации первой и второй степени в социальной рекламе

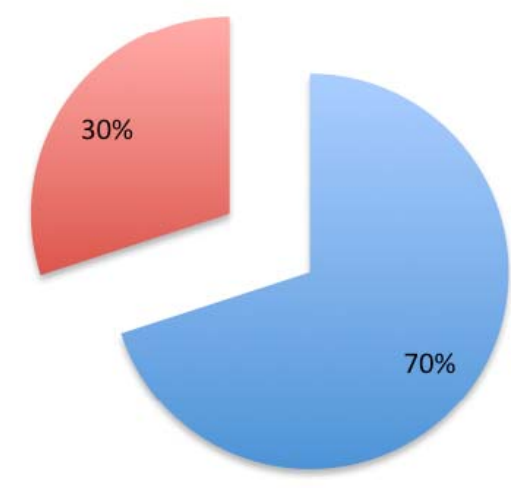

В рамках проведенного нами исследования социальные и коммерческие слоганы с использованием ФЕ демонстрируют стойкую тенденцию к реализации контекстуальных трансформаций, в том числе осложненных стилистических приемов, и это несмотря на малую протяженность рекламного текста. Особенно показательно сравнение языка рекламы и художественной литературы: в рамках последнего на узуальное использование ФЕ приходится около $70 \%$, а на окказиональные трансформации - 30\% тогда как в рекламных слоганах ситуация обратная: около 30 и около 70\% сответственно (рис. 1, 2).

2.2. Контекстуальная реализация ФЕ как средство, способное оживить накопленный опыт

Функции и цели слогана огромны и разнообразны, они не могут быть реализованы без определенного синтаксического построения фразы, а также без определенных лексических и других речевых средств. Поэтому копирайтеры стремятся привлечь внимание потребителя различными способами: используя семантико-стилистические свойства слов, структурные особенности предложения, фонетико-интонационные, а также графические средства. В условиях жесткой конкуренции СМИ, стараясь привлечь потребителя всеми возможными способами, для описания объекта рекламы пользуются наиболее яркими и запоминающимися выражениями. Это влечет за собой широкое использование фразеологического материала: образность устойчивых словосочетаний уже содержит устоявшуюся эмоциональную окраску; мысль, сформулированная с помощью ФЕ, лучше воспринимается, так как фразеологизмы известны практически любому человеку; в связи с широкой известностью фразеологизмов их легко трансформировать и изменять, поэтому копирайтеры нередко прибегают к приему трансформации ФЕ.

Копирайтеры пользуются различными приемами, в частности прибегают к трансформации фразеологических единиц. Такая тенденция к модификации устойчивых сочетаний стала стратегической в рамках рекламной коммуникации, поскольку ФЕ способна оживлять накопленный опыт: «Слова, фразеологизмы и афоризмы имеют, наряду с номинативной, еще и кумулятивную функцию - фиксации, хранения и передачи немалого объема информации о постигнутой обществом действительности» [4. С. 195]. Таким образом, рек- 
ламные слоганы, содержащие в себе трансформированные фразеологизмы, в том числе коммуникативные $Ф Е$, легко находят путь к сознанию адресата.

Однако есть существенное отличие слогана, имеющего противоположно направленный от паремии вектор развития. В статье «Рекламный слоган как трансформация культурных стереотипов» В.В. Бегун пишет: «Если паремия вырастает из опыта, то рекламный слоган сам создает опыт. Рекламный слоган, в отличие от традиционной паремии, не имеет проверенных временем ценностных корней. Но, заимствуя у паремии ее структуру, остов, легко узнаваемую схему, рекламный слоган добивается того, что формальное подобие рождает иллюзию содержательной близости» [5. С. 35]. Существует опыт, что слоганы входили в категорию фразеологизмов, использовались как основа для следующего поколения рекламных текстов и модифицировались.

Такой прием является достаточно продуктивным в сфере рекламы, о чем свидетельствует тот факт, что копирайтеры нередко прибегают к созданию слоганов по уже известной структурной модели. Так, например, с возникновением рекламы визуальной, к которой также относится реклама на плакатах, связано создание рекламного текста «One drive is worth a thousand words» («Одна поездка вместо тысячи слов») для фирмы «Форд». Слоган стал своеобразной производной от лозунга «One Look is Worth a Thousand Words» («Один взгляд вместо тысячи слов») менеджера по рекламе Фреда Р. Барнарда (Fred R. Barnard), который в 1921 г. стоял на пороге эпохи визуальной рекламы. Создатель краткого рекламного текста напечатал его на журнальном развороте, при этом не дополнив текст изображением. Этот акт стал персональным призывом Ф.Р. Барнарда использовать визуальный образ в рекламе для достижения ее эффективности. Позже менеджер по рекламе изменил свой прежний слоган на «Chinese Proverb: One Picture Is Worth Ten Thousand Words» («Китайская пословица гласит: одно изображение вместо десяти тысяч слов»). В дальнейшем по аналогичной структурной модели («A (One) $\mathrm{X}$ is worth a thousand (million) words») был создан не один рекламный слоган [6. C. 79], а в языке закрепилась устойчивая единица «ріcture is worth a thousand words».

2.3. Окказиональные конфигурачии первой и второй степени в рекламных слоганах

ФЕ в контексте рекламы могут быть реализованы как узуально, так и окказионально. А.В. Кунин в своих исследованиях предложил четыре типа конфигураций, которые образуют фразеологизм и его актуализатор. К первым двум типам относится узуальная конфигурация первой и второй степени. Принципиальное отличие между ними заключается в усилении экспрессивности ФЕ в рамках узуальной конфигурации второй степени посредством «позиционных стилистических приемов» [7. С. 244]. Ко вторым двум разновидностям относится окказиональная конфигурация первой и второй степени.

В рамках окказиональной конфигурации первой степени происходит не только усиление экспрессивности, но и возможен ряд изменений в значении и структуре ФЕ. Это достигается посредством использования таких стилистических приемов, как двойная актуализация, вклинивание, замена, разорванное использование, эллипсис, добавление и т.д. Двойная актуализация действительно играет большую роль в языке рекламы: наряду с заменой ком- 
понента двойная актуализация является одним из частотных стилистических приемов, который может также сочетаться с другими разновидностями окказиональной трансформации. Тем не менее не все стилистические преобразования могут быть реализованы на материале рекламных слоганов: так, например, разорванное использование ФЕ свойственно диалогической речи; в монологическойречи прием подразумевает использование вводных конструкций, что не характерно для языка рекламы.

Окказиональная конфигурация второйстепени представляет собой преобразования, реализуемые с помощью сложных стилистических приемов, в том числе конвергенции - единовременного использования нескольких стилистических приемов. Несмотря на малую протяженность рекламного текста, мы не можем говорить об отсутствии осложненных стилистических приемов: проведенный анализ показал, что на практике реализуются приемы расширенной фразеологической метафоры, фразеологического насыщения контекста и др.

Таблица 1. Узуальная и окказиональная конфигурации в коммерческой и социальной рекламе в вертикальном срезе

\begin{tabular}{|l|r|r|r|}
\hline \multicolumn{2}{|l|}{} & коммерческая реклама & \\
\hline Окказиональная конфигурация 1 степени & русский & английский & немецкий \\
\hline двойная актуализация & $26 \%$ & $34 \%$ & $19 \%$ \\
\hline замена & $35 \%$ & $30 \%$ & $47 \%$ \\
\hline усечение & $17 \%$ & $6 \%$ & $18 \%$ \\
\hline расширение & $2 \%$ & $10 \%$ & $0 \%$ \\
\hline перестановка & $9 \%$ & $2 \%$ & $1 \%$ \\
\hline Окказиональная конфигурация 2 степени & русский & английский & немецкий \\
\hline фразеологическая аллюзия & $0 \%$ & $0 \%$ & $4 \%$ \\
\hline расширенная метафора & $2 \%$ & $8 \%$ & $3 \%$ \\
\hline конвергенция, фразеологическое насыщение контекста & $9 \%$ & $10 \%$ & $8 \%$ \\
\hline \multicolumn{2}{|r|}{} \\
\hline Окказиональная конфигурация 1,2 степени & & \multicolumn{3}{|r|}{} \\
\hline Узуальная конфигурация & $81 \%$ & $75 \%$ & $82 \%$ \\
\hline
\end{tabular}

\begin{tabular}{|l|r|r|r|}
\hline & \multicolumn{1}{|c|}{ социальная реклама } & \\
\hline Окказиональная конфигурация 1 степени & русский & английский & немецкий \\
\hline двойная актуализация & $31 \%$ & $25 \%$ & $6 \%$ \\
\hline замена & $31 \%$ & $33 \%$ & $44 \%$ \\
\hline усечение & $25 \%$ & $13 \%$ & $31 \%$ \\
\hline расширение & $6 \%$ & $4 \%$ & $0 \%$ \\
\hline перестановка & $6 \%$ & $4 \%$ & $0 \%$ \\
\hline Окказиональная конфигурация 2 степени & русский & английский & немецкий \\
\hline фразеологическая аллюзия & $0 \%$ & $13 \%$ & $0 \%$ \\
\hline расширенная метафора & $0 \%$ & $4 \%$ & $0 \%$ \\
\hline конвергенция, фразеологическое насыщение контекста & $0 \%$ & $4 \%$ & $19 \%$ \\
\hline \multicolumn{2}{|l|}{} & & \multicolumn{3}{|c|}{} \\
\hline Окказиональная конфигурация 1, 2 степени & $89 \%$ & $65 \%$ & $64 \%$ \\
\hline Узуальная конфигурация & $11 \%$ & $35 \%$ & $36 \%$ \\
\hline
\end{tabular}


В слоганах для коммерческой и социальной разновидностей рекламы на русском, английском и немецком языках используются такие стилистические приемы окказиональной конфигурации первой степени, как двойная актуализация, замена компонента/компонентов ФЕ (субституция), усечение компонентного состава ФЕ (эллипсис), расширение компонентного состава ФЕ (добавление, вклинивание) и перестановка компонентов ФЕ. Окказиональная конфигурация второй степени в кратких рекламных текстах представлена следующими стилистическими приемами: расширенная фразеологическая метафора, фразеологическая аллюзия, конвергенция и фразеологическое насыщение контекста (см. табл. 1,2).

Таблица 2. Узуальная и окказиональная конфигурации в коммерческой и социальной рекламе в горизонтальном срезе

\begin{tabular}{|l|r|r|r|}
\hline & \multicolumn{1}{|l|}{ коммерческая реклама } & \\
\hline Окказиональная конфигурация 1 степени & русский & английский & немецкий \\
\hline двойная актуализация & $31 \%$ & $38 \%$ & $31 \%$ \\
\hline замена & $28 \%$ & $22 \%$ & $50 \%$ \\
\hline усечение & $36 \%$ & $12 \%$ & $52 \%$ \\
\hline расширение & $17 \%$ & $83 \%$ & $0 \%$ \\
\hline перестановка & $71 \%$ & $14 \%$ & $14 \%$ \\
\hline Окказиональная конфигурация 2 степени & русский & английский & немецкий \\
\hline фразеологическая аллюзия & $0 \%$ & $0 \%$ & $100 \%$ \\
\hline расширенная метафора & $14 \%$ & $57 \%$ & $29 \%$ \\
\hline конвергенция, фразеологическое насыщение контекста & $31 \%$ & $31 \%$ & $38 \%$ \\
\hline Узуальная конфигурация & $28 \%$ & $37 \%$ & $35 \%$ \\
\hline
\end{tabular}

\begin{tabular}{|l|r|r|r|}
\hline & \multicolumn{1}{|l|}{ социальная реклама } & \\
\hline Окказиональная конфигурация 1 степени & русский & английский & немецкий \\
\hline двойная актуализация & $42 \%$ & $50 \%$ & $8 \%$ \\
\hline замена & $25 \%$ & $40 \%$ & $35 \%$ \\
\hline усечение & $33 \%$ & $25 \%$ & $42 \%$ \\
\hline расширение & $50 \%$ & $50 \%$ & $0 \%$ \\
\hline перестановка & $50 \%$ & $50 \%$ & $0 \%$ \\
\hline Окказиональная конфигурация 2 степени & русский & английский & немецкий \\
\hline фразеологическая аллюзия & $0 \%$ & $100 \%$ & $0 \%$ \\
\hline расширенная метафора & $0 \%$ & $100 \%$ & $0 \%$ \\
\hline конвергенция, фразеологическое насыщение контекста & $0 \%$ & $25 \%$ & $75 \%$ \\
\hline Узуальная конфигурация & $8 \%$ & $54 \%$ & $38 \%$ \\
\hline
\end{tabular}

Проведенный нами анализ практического материала показал примерное численное равенство слоганов с использованием ФЕ в коммерческой рекламе на трех языках, тогда как социальные слоганы с ФЕ на английском языке количественно превалируют. Кроме того, существует стойкая тенденция к реализации контекстуальных трансформаций, обусловленных как интра-, так и экстралингвистическими факторами.

Так, повышенный интерес к стилистическим приемам двойной актуализации (38\%) и расширенной фразеологической метафоры $(57 \%)$ на английском языке (в горизонтальном срезе) можно объяснить многовековой традицией англоязычного населения творческого обыгрывания языка, языковой игры, которая отмечается многими исследователями. 
Например, «Success didn't go to his head, it went to his neighbor» ${ }^{1}-$ оригинальный слоган к фильму «Еnvy» («Черная зависть»), 2003 г., США [8]. Основой слогана послужила номинативная ФЕ со структурой подчинительного словосочетания «go to one's head», которая в русском языке имеет экспрессивный разговорный аналог «ударить в голову», используемый в значении «помрачить рассудок». В данном примере мы наблюдаем обыгрывание части ФЕ «<..> didn't go to his head - went to his neighbor» за счет использования расширенной метафоры, а также добавления отрицания («didn't»).

«Roll up your sleeves» ${ }^{2}$ - слоган для социальной кампании, направленной на привлечение внимания к акции донорской сдачи крови, проводимой организацией по оказанию гуманитарной помощи в США «American Red Cross», 1972 г. [9]. Данный краткий рекламный текст был создан с использованием номинативно-коммуникативной $\Phi \mathrm{E}$ «to roll up one's sleeves», которую можно интерпретировать как в прямом, так и в переносном значении: в первом случае фразеологизм имеет значение «засучить рукава», во втором - «приготовиться к усердной работе». Здесь мы наблюдаем прием двойной актуализации, когда имеет место не только использование ФЕ в ее переосмысленном значении, но и в прямом: слоган для социальной рекламной кампании призывает общественность в прямом смысле «засучить рукава» и стать добровольными донорами крови в специально отведенный для данной акции день.

В немецкоязычных коммерческих и социальных слоганах одним из наиболее частотных в горизонтальном срезе является прием усечения компонента/компонентов ФЕ (52 и 42\% соответственно): повышенное внимание к приему усечения компонентного состава со стороны немецких копирайтеров может отражать общие для немецкого языка тенденции к экономии немецких языковых средств и, соответственно, сокращению:

«Ich fuhl mich wohl in meiner Haut» ${ }^{3}$ - слоган для фирмы-производителя продукции по уходу за кожей «Florena» [9]. В основу краткого рекламного текста положена $\Phi \mathrm{E}$ «sich nicht wohl in seiner Haut fühlen», имеющая русскоязычный аналог «чувствовать себя не в своей тарелке» в значении «быть стесненным, скованным». В данном примере мы наблюдаем усечение отрицания «nicht» в середине ФЕ. Кроме того, обыгрывание компонента ФЕ «Haut» («кожа») подчеркивает результат действия рекламируемого продукта: благодаря данному крему потребитель «находится в гармонии с собой и со своей кожей».

«Vielleicht macht Geld glü̈klich. Aber wer weiß schon, was Glük ist?» ${ }^{4}-$ слоган к полнометражному фильму «Neben der Spur», Германия, 2008 г., драма [8]. В основу краткого рекламного текста положена коммуникативная ФЕ «Geld allein macht nicht glücklich», которая используется в значении «не в деньгах счастье». В данном примере мы наблюдаем следующие преобразования: усечению подверглись наречие «allein» («только», «исключительно») и отрицательная частица «nicht». Кроме того, создатели слогана расширили

\footnotetext{
${ }^{1}$ База слоганов [Электронный ресурc]. URL: http://www.kinopoisk.ru/

2 База слоганов [Электронный ресурc]. URL: http://www.slogans.de/

${ }^{3}$ База слоганов [Электронный ресурс]. URL: http://www.slogans.de/

${ }^{4}$ База слоганов [Электронный ресурc]. URL: http://www.kinopoisk.ru/
} 
контекст предложения с помощью добавления наречия «vielleicht» («возможно, вероятно»), что привело к появлению семантического оттенка гипотетической модальности, которая усиливается благодаря добавлению риторического вопроса «Aber wer weiß schon, was Glück ist?» («Кто знает, что такое счастье?»). Таким образом, благодаря приему усечения сочетание слов было приближено к нуждам коммерческой рекламной кампании, а модифицированное значение $\Phi Е$, положенной в основу слогана, заранее дает представление о сюжете фильма.

В коммерческой рекламе на русском языке широко представленным в горизонтальном срезе является прием перестановки компонентов, который составил $71 \%$ от всех случаев его использования в трех языках. Это обусловлено синтаксическими особенностями русского языка, в частности свободным порядком слов и, следовательно, возможностью варьировать положение компонентов в предложении.

Рассмотрим слоган «Из воды сухим не выйии» ${ }^{l}$ к фильму «No Country for Old Men» («Старикам тут не место»), 2007 г., США [8]. Номинативная ФЕ «выйи сухим из воды» в результате структурно-семантического преобразования приобрела необходимую семантику за счет вклинивания отрицательной частицы «не», а инверсия сделала эмфатическое ударение на образности, заложенной во ФЕ.

Еще один пример, который иллюстрирует прием перестановки компонентов, - слоган для рекламы лакокрасочных изделий «Не место красит человека, $a$ человек место» ${ }^{2}$ [10]. Краткий рекламный текст создан с использованием коммуникативной $\Phi \mathrm{E}$ «не место человека, а человек место красит». В данном случае мы наблюдаем перестановку компонента-глагола «красит», благодаря которой обыгрывается не только переосмысленное, но и прямое значение слов, входящих в состав фразеологизма: подразумевается, что человек в буквальном смысле слова красит место краской - рекламируемой продукцией.

\section{3. Выводы}

В результате исследования мы пришли к выводу, что в слоганах коммерческой и социальной рекламы на трех языках реализуются следующие стилистические приемы окказиональной конфигурации первой степени: двойная актуализация, замена компонента/компонентов ФЕ (субституция), усечение компонентного состава ФЕ (эллипсис), расширение компонентного состава ФЕ (добавление, вклинивание) и перестановка компонентов ФЕ. Окказиональная конфигурация первой степени была реализована в $68 \%$ случаев в коммерческой рекламе и в $60 \%$ - в социальной. Окказиональная конфигурация второй степени в языке рекламы представлена такими стилистическими приемами, как расширенная фразеологическая метафора, фразеологическая аллюзия, конвергенция и фразеологическое насыщение контекста. Окказиональная конфигурация второй степени составила $11 \%$ от всех конфигураций в коммерческой рекламе и $10 \%$ - в социальной. Узуальное использование ФЕ было реализовано в $21 \%$ случаев в коммерческой и в $30 \%$ в социальной рекламе.

\footnotetext{
${ }^{1}$ База слоганов [Электронный ресурc]. URL: http://www.kinopoisk.ru/

${ }^{2}$ База слоганов [Электронный ресурc]. URL: http://www.textart.ru/
} 
Говоря о количественном соотношении стилистических приемов по языкам в горизонтальном срезе, важно отметить, что в коммерческой рекламе прием двойной актуализации чаще всего встречается в слоганах на английском языке (38\%). Такой повышенный интерес к данному стилистическому приему объясняется национальными особенностями: английский юмор называют тонким, поскольку значительное количество шуток, анекдотов и острот построено на двусмысленности той или иной фразы или же каламбуре. Интерес к данному приему обусловлен как национальными особенностями, так и эффективностью использования двусмысленности восприятия ФЕ в качестве риторического и стилистического приемов в сфере коммерческой рекламы. Кроме того, такие приемы, как расширение компонентного состава ФЕ и расширенная фразеологическая метафора, также активно представлены на материале англоязычных коммерческих слоганов и составили 83 и 57\% соответственно.

В слоганах на немецком языке чаще других используются приемы усечения и замены компонента/компонентов ФЕ: в коммерческой рекламе приемы составили около $50 \%$ от всех примеров на трех языках. Замена действительно является частотным приемом, а повышенное внимание к приему усечения компонентного состава со стороны немецких копирайтеров может отражать общие для немецкого языка тенденции к экономии немецких языковых средств и, соответственно, сокращению. Кроме того, в коммерческих слоганах на немецком языке представлен такой осложненный прием, как фразеологическая аллюзия.

Интересным результатом анализа практического материала послужили данные относительно стилистического приема перестановки компонентов $Ф Е$. Необходимо отметить повышенный интерес отечественных копирайтеров к данному приему: в коммерческой рекламе прием перестановки компонентов составил $71 \%$ от всех случаев его использования в трех языках. Это обусловлено синтаксическими особенностями русского языка, в частности свободным порядком слов и, следовательно, возможностью варьировать положение компонентов в предложении.

Показательным по результатам проведенного исследования является то, насколько частотно представлены стилистические преобразования, реализованные на материале коммерческой и социальной разновидностей рекламы: окказиональная конфигурация первой и второй степени была зафиксирована в $79 \%$ случаев в коммерческой рекламе и в $70 \%$ - в социальной. Для сравнения: узуальное использование ФЕ было реализовано в $21 \%$ случаев в коммерческой и в $30 \%$ в социальной рекламе. Это свидетельствует об активном процессе трансформации фразеологизмов в языке рекламы по сравнению с языком художественной литературы, где ФЕ, используемых узуально, в среднем около $70 \%$, что иллюстрирует обратную ситуацию.

\section{4. Заключение}

Таким образом, фразеологизмы в рекламных слоганах редко функционируют без стилистических преобразований: творческое использование $Ф Е$ в рекламном слогане служит эффективным способом аттракции потенциального потребителя, поскольку рекламный текст, содержащий модифицированные фра- 
зеологизмы, отличают образность, экспрессивность, высокая читаемость и запоминаемость, оригинальность, выразительность и пр. Благодаря лаконичности, семантической емкости, воспроизводимости в готовом виде в речи, устойчивости, общеизвестности носителю языка, а также другим аспектам ФЕ представляет собой находку для творцов кратких рекламных текстов, которые используют стилистические преобразования фразеологизмов для того, чтобы приблизить их семантику к нуждам и целям рекламной кам-пании.

Тем не менее проведенный нами анализ практического материала показал, что выбор в пользу того или иного стилистического приема определяется не только прагматикой рекламной кампании, но и закрепленной во фразеологизмах культурной информацией, структурой языка, а также ментальностью его носителя. Образность, заложенная во ФЕ, свидетельствует о своеобразии национальноспецифической картины мира и мышления носителей того или иного языка, которые, в свою очередь, находят отражение в рекламном тексте.

Фразеологизм, рассматриваемый вне контекста, является не чем иным, как статичным образованием. Однако границы фразеологии на этом не заканчиваются; напротив, семантика ФЕ раскрывается лишь в практическом, контекстуальном употреблении, в частности в языке кратких рекламных слоганов. Стилистические изменения фразеологизмов не только стимулируют обновление метафорической мысли, но и способствуют языковому изменению и развитию в целом.

\section{Лumepamypa}

1. Телия, В.Н. Русская фразеология: Семантический, прагматический и лингвокультурологический аспекты. М.: Языки русской культуры, 1996. 288 с.

2. Костомаров В.Г. Наш язык в действии: Очерки современной русской стилистики. М.: Гардарики, 2005. $287 \mathrm{c}$.

3. Naciscione A. Stylistic Use of Phraseological Units in Discourse. Amsterdam/Philadelphia: John Benjamins Publishing Company, 2010. 239 p.

4. Верещагин Е.M., Костомаров В.Г. Язык и культура. Три лингвострановедческие концепции: лексического фона, рече-поведенческих тактик и сапиентемы / под ред. и с послесловием Ю.С. Степанова. М.: Индрик, 2005. 1040 с.

5. Бегун В.B. Рекламный слоган как трансформация культурных стереотипов // Вестн. Перм. ун-та. Российская и зарубежная филология. 2010. № 1 (7). С. 31-37.

6. Mieder W. Proverbs: A Handbook / W. Mieder. Westport, Connecticut: Greenwood Press, 2004. $305 \mathrm{p}$.

7. Кунин А.В. Курс фразеологии современного английского языка. 3-е изд., стер. Дубна: Феникс+, 2005. 488 c

8. База рекламных слоганов [Электронный ресурc]. URL: http://www. kinopoisk.ru/

9. База рекламных слоганов [Электронный ресурс]. URL: http://www.slogans.de/

10. База рекламных слоганов [Электронный ресурс]. URL: http://www.textart.ru/

LINGUOCULTUROLOGICAL ASPECTS OF THE CONTEXTUAL USE OF PHRASEOLOGICAL UNITS IN ADVERTISING SLOGANS

Vestnik Tomskogo gosudarstvennogo universiteta. Filologiya - Tomsk State University Journal of Philology. 2017. 45. 139-149. DOI: 10.17223/19986645/45/10

Nina P. Soboleva, Kazan (Volga Region) Federal University (Kazan, Russian Federation). E-mail: NPSoboleva@kpfu.ru

Keywords: phraseological unit, advertising slogan, occasional use, cultural and national identity. 
The paper aims at a comparative analysis of aspects of usual and occasional use of phraseological units (PUs) in the context of social and commercial slogans for products, services and feature-length films in Russian, English and German in order to identify the main trends in the contextual implementation of PUs by reference to a linguoculturological approach. The practical material for the analysis was 18 thousand slogans in Russian, English and German. Description of the analyzed material is presented in the form of a table, where contextual configurations are arranged vertically and languages at issue are placed horizontally. The quantitative analysis of the material under study based on comparison is carried out in the vertical (all the cases of contextual use of PUs are considered within one language) and horizontal (each contextual configuration is considered separately in three languages) sections.

Phraseology is a special area of linguistics within which language, culture, history and world view of a particular ethnic group are most closely intertwined. Phraseological units being conductors into a particular culture often function in the language of advertising, which implies the use of usual and occasional phraseological units as verbal means of recipients' attraction. The comparative nature of the research which covers the analysis of slogans in three languages and a multifaceted approach to the analysis of the practical material under study determine the relevance of the study.

As a result of the carried out research the author came to a conclusion that there is an active process of transformation of PUs in the language of advertising in comparison with the language of fiction literature. The analysis of the practical material under study has shown that the choice in favor of a particular stylistic device is determined not only by the pragmatics of an advertising campaign, but also by cultural information, structure of language and mentality fixed in PUs. Imagery embedded in PUs stipulates for the uniqueness of the nation-specific picture of the world and thinking of native language speakers which, in turn, are also reflected in the advertising text.

Intense interest towards the use of stylistic patterns of pun and extended phraseological metaphor in English can be explained by the centuries-old tradition of the English-speaking population to creatively play upon the language and words, which is noted by many researchers. The German-language taglines illustrate the frequency of the usage of ellipsis, which reflects a common tendency of the German language towards the realization of linguistic economy and corresponding reduction. Permutation is widely used in the Russian-language taglines due to the syntactic peculiarities of the Russian language, its relatively free word order and, consequently, the ability to vary the position of the constituents within the sentence.

\section{References}

1. Teliya, V.N. (1996) Russkaya frazeologiya. Semanticheskiy, pragmaticheskiy i lingvokul'turologicheskiy aspekty [Russian phraseology. Semantic, pragmatic and linguoculturological aspects]. Moscow: Yazyki russkoy kul'tury.

2. Kostomarov, V.G. (2005) Nash yazyk v deystvii: Ocherki sovremennoy russkoy stilistiki [Our language in action: Essays on modern Russian stylistics]. Moscow: Gardariki.

3. Naciscione, A. (2010) Stylistic Use of Phraseological Units in Discourse. Amsterdam/Philadelphia: John Benjamins Publishing Company.

4. Vereshchagin, E.M. \& Kostomarov, V.G. (2005) Yazyk i kul'tura. Tri lingvostranovedcheskie kontseptsii: leksicheskogo fona, reche-povedencheskikh taktik i sapientemy [Language and culture. Three linguistic country study concepts: lexical background, speech behavioral tactics and sapientheme]. Moscow: Indrik.

5. Begun, V.V. (2010) Advertising slogans as cultural stereotypes transformation. Vestnik Permskogo universiteta. Rossiyskaya i zarubezhnaya filologiya - Perm University Herald. Russian and Foreign Philology. 1 (7). pp. 31-37. (In Russian).

6. Mieder, W. (2004) Proverbs: A Handbook. Westport, Connecticut: Greenwood Press.

7. Kunin, A.V. (2005) Kurs frazeologii sovremennogo angliyskogo yazyka [Course of modern English phraseology]. 3rd ed. Dubna: Feniks+.

8. Advertising slogans database. [Online] Available from: http://www.kinopoisk.ru/. (In Russian).

9. Advertising slogans database. [Online] Available from: http://www.slogans.de/. (In German).

10. Advertising slogans database. [Online] Available from: http://www.textart.ru/. (In Russian). 